\title{
Blind Obedience to Environmental Friendliness: The Goal Will Set Us Free
}

\author{
Bohee Jung ${ }^{1}$ and Jaewoo Joo ${ }^{2, * \mathbb{D}}$ \\ 1 Department of Business Administration, College of Business Economics, Hannam University, 70 Hannam-ro, \\ Daedeok-gu, Daejon 34430, Korea; bohee@hnu.kr \\ 2 Department of Marketing, College of Business Administration, Kookmin University, 77 Jeongneung-ro, \\ Seongbuk-gu, Seoul 02707, Korea \\ * Correspondence: designmarketinglab@gmail.com; Tel.: +82-2-910-5523
}

Citation: Jung, B.; Joo, J. Blind Obedience to Environmental Friendliness: The Goal Will Set Us Free. Sustainability 2021, 13, 12322. https://doi.org/10.3390/ su132112322

Academic Editor: Colin Michael Hall

Received: 28 September 2021

Accepted: 3 November 2021

Published: 8 November 2021

Publisher's Note: MDPI stays neutral with regard to jurisdictional claims in published maps and institutional affiliations.

Copyright: (c) 2021 by the authors. Licensee MDPI, Basel, Switzerland. This article is an open access article distributed under the terms and conditions of the Creative Commons Attribution (CC BY) license (https:// creativecommons.org/licenses/by/ $4.0 /)$.

\begin{abstract}
In the past, researchers focusing on environmentally friendly consumption have devoted attention to the intention-action gap, suggesting that consumers have positive attitudes toward an environmentally friendly product even though they are not willing to buy it. In the present study, we borrow insights from the behavioral decision making literature on preference reversal to introduce an opposite phenomenon - that is, consumers buying an environmentally friendly product even though they do not evaluate it highly. We further rely on the research on goals to hypothesize that choiceevaluation discrepancies disappear when consumers pursue an environmentally friendly goal. A two (Mode: Choice vs. Evaluation) by three (Goal: Control vs. Quality vs. Environmentally friendly) between-subjects experimental design was used to test the proposed hypotheses. Our findings obtained from 165 undergraduate students in Korea showed that, first, 76\% of the participants chose an environmentally friendly cosmetic product whereas only $49 \%$ of the participants ranked it higher than a competing product, and, second, when participants read the sentence "You are now buying one of the two compact foundations in order to minimize the waste of buying new foundations," the discrepancy disappeared (64\% vs. 55\%). Our experimental findings advance academic discussions of green consumption and the choice-evaluation discrepancy and have practical implications for eco-friendly marketing.
\end{abstract}

Keywords: behavioral decision making; environmentally friendly; choice-evaluation discrepancy; intention-action gap; preference reversal; goal

\section{Introduction}

Contemporary consumers may report positive attitudes towards an environmentally friendly product but they do not actually buy it, which raises the issue of the "intentionaction gap." According to a McKinsey report, for instance, about $80 \%$ of Chinese and Indian respondents indicated that they were willing to pay more for sustainable packaging [1]. This report highlights that "environmental concerns are at the forefront of the minds of consumers in emerging Asia." However, another report published by the same company pointed out that "intentions expressed in surveys may not always translate into actual purchases because effective premiums for sustainable products often exceed 30 percent" [2]. Findings from the two reports were echoed in another survey which showed that $65 \%$ of the respondents wanted to buy purpose-driven brands that advocate sustainability, yet only $26 \%$ actually did so [3]. As a result, scholars focusing on environmentally friendly consumption devoted attention to closing the gap between intention and action. One proposed solution was to form a habit by making sustainable behavior the default and using prompt and feedback [3]. Another proposed solution was to activate status motives, based on experimental findings that among participants who read a story in which they have an opportunity to receive a desirable promotion their desire for a dishwasher with a recirculating water system that would save water increased [4]. The second solution was 
supported by a recent survey showing that the more strongly people sought status, the greater their purchase intention was for a 100\%-recycled notebook [5].

Although prior research on the topic of the intention-action gap demonstrates exclusively that people's intentions to purchase environmentally friendly products are stronger than their actions, actions could be stronger than intentions. Take an example of free reusable cups distributed by Starbucks Korea to celebrate the 25th anniversary of the founding of global Starbucks. Starbucks cups have been hunted by resellers and appeared immediately on online second-hand marketplaces. According to a newspaper report of 28 September 2021, on Korean second-hand online markets, such as Carrot Market or Bungae Janger, "the cups are being offered for 4000 won (\$3.8) to 8000 won each. Cups offered at around 4000 won are already shown as sold out" (https:/ / koreajoongangdaily.joins.com/20 21/09/28/business/industry/starbucks-reusablecups/20210928163611431.html, accessed on 4 November 2021). Criticism was being raised and the Green Washing controversy, which refers to the camouflage environmental movement, has been sparked by this reusable cup event because the reusable cup is made of PP (polypropylene) and emits the same amount of greenhouse gas as the material used to make plastic bottles during the manufacturing and disposal processes (https://koreajoongangdaily.joins.com/2019/07/23 / features / Is-collecting-ecofriendly-items-really-helping-the-environment-In-an-effort-towaste-less-we-may-be-doing-more-damage/3065855.html, accessed on 4 November 2021). Similar examples are Jil Sander's brown bag, which costs $\$ 290$ but is rendered from coated brown paper and features the logo on the bottom, and the Freitag messenger bag, which costs $\$ 200$ but is cut out of old truck tarpaulins with a second-hand car seatbelt as a carry belt and an old bicycle inner tube as an edging.

Note that the rarely documented but frequently observed phenomena that people act in spite of their intentions in the environmentally friendly consumption context could be attributed to so-called "choice-evaluation inconsistency." According to numerous experimental findings, researchers have reached a consensus that people do not have a well-defined set of preferences. Instead, they construct their preference on the spot. Therefore, their preferences are shaped depending on how the items they range over are presented [6]. This inconsistency has been much documented and extensively discussed since the 1970s [7].

We have two purposes for the present study. First, we aim to demonstrate the choiceevaluation inconsistency in the context of environmentally friendly consumption. More specifically, we propose that when consumers make a choice, they may put too much emphasis on environmental friendliness. Therefore, they may choose an environmentally friendly product that they do not evaluate highly, resulting in a discrepancy between choice and evaluation. Second, we aim to suggest how to overcome the choice-evaluation inconsistency. We borrow insights from the literature on goals and examine whether asking consumers to pursue a goal eliminates the proposed discrepancy. In sum, the two questions we aim to address are: (1) whether people show a discrepancy between choice and evaluation of an environmentally friendly product; and (2) whether the choiceevaluation discrepancy is eliminated when a goal is pursued.

The present work will advance the academic discussion of these two areas. Firstly, we add to the literature on environmentally friendly consumption by introducing an unprecedented phenomenon. To the best of our knowledge, extensive prior research has shed light on the under-choice of environmentally friendly products, while no attention has been paid to over-choice [3]. Secondly, we add to the literature on the choice-evaluation discrepancy by applying it to a novel context - that is, environmental friendliness. One of the few contexts in which choice-evaluation discrepancy has been much discussed is conjoint analysis [8].

This work will also have practical implications for eco-friendly marketing communications. Most importantly, marketers will gain insights into how to ask a question. When they promote environmentally friendly products, they should use a choice format. Instead, when they promote non-environmentally friendly products, they should use an evaluation 
format. Further, they will be able to sharpen their knowledge by learning that discrepancies can disappear depending on which consumption goals consumers pursue.

This article is organized as follows. First, we develop understanding about environmentally friendly attributes. We conceptualize environmentally friendly attributes as negatively associated with quality attributes. Secondly, we review the literature on the discrepancy between choice and evaluation to develop our first hypothesis. Next, we review the literature on consumption goals to develop our second hypothesis. Then, we elaborate our experimental study and report its findings. Finally, we discuss the academic contributions and managerial implications of our findings, concluding with a consideration of the limitations of the present study and suggestions for future research.

\section{Theory and Hypotheses}

\subsection{Environmental Friendliness}

Although environmentally friendly consumption includes several issues, such as involvement in environmental-caring activities (e.g., recycling packaging), one of the critical issues for consumers is that they have to sacrifice something to pursue environmental friendliness. This is because consumers believe there is often a trade-off relationship between environmental friendliness and an attribute of a product [9].

The most frequently and regularly observed in the real world is the trade-off relationship between environmental friendliness and price. One experiment demonstrated that participants wanted to pay less for the computer manufactured by a company which discharges poisonous chemical waste [10]. Another experiment showed that participants were less incline to purchase a cheaper product when an environmentally friendly product was recommended [11].

In contrast, the trade-off relationship between environmental friendliness and performance has attracted relatively less attention. This relationship, however, is due to the fact that consumers often associate environmental friendliness with gentleness. Therefore, when they consider buying a product which needs strong performance (e.g., car wash), an environmentally friendly option is not considered [12]. Consumers also associate environmental friendliness with inefficiency. They tend to consume an environmentally friendly detergent more than a typical one [13]. Indeed, as Mostafa [9] stated, one of the five critical issues for environmentally friendly consumption is that consumers have to accept a lower technical performance for the products purchased in exchange for better eco-performance.

As prior literature suggests, we consider that a green product is superior on an environmentally friendly attribute while inferior on another aspect, such as quality, compared to a non-green product.

\subsection{Preference Reversal}

The classical theory of preference assumes that people have a well-defined preference set and their preferences do not depend on the method of preference elicitation [7]. However, the growing belief among decision theorists is that people construct their preferences on the spot and preferences depend on methods of assessment, violating the assumption of procedure invariance [7]. Early work in this area contrasted choice with bidding or matching. In Lichtenstein and Slovic's [6] original demonstration, for instance, participants were asked to indicate their preference between two bets of almost equal expected value. One (P-bet) has a higher probability of winning a modest amount and the other (\$-bet) has a smaller probability of winning a large amount. They found that, when asked to choose between two bets presented together, more participants chose P-bet. However, when asked to bid two bets presented separately, \$-bet received a higher bid amount.

Historically, researchers have explained preference reversal by relying on prominence effect. More specifically, when an option has a prominent attribute, people are more likely to choose it but do not evaluate it highly. Lichtenstein and Slovic [6] argue that choice is determined by probability, while bid is determined by winning amount, because participants made choice decisions in a non-compensatory way, whereas they made bidding 
decisions in a compensatory way. Tversky et al. [14] extended this argument and proposed that when choosing one option, people tend to select an option that is superior with respect to the prominent (most important) attribute, whereas, when matching two options, they tend to trade off the differences on the prominent attribute. Later, Fischer and Hawkins [15] generalized prominence effect to the strategy-compatibility hypothesis. According to them, people seek out the compatibility between the meta-property of response (qualitative vs. quantitative) and the meta-property of decision strategy (ordering attribute importance vs. making trade-off). Therefore, the qualitative response mode (e.g., choice) enhances the preference for the option that is superior on the most important attribute (e.g., price), which contrasts with the quantitative response mode (e.g., rating or pricing).

We propose that environmental friendliness is prominent (most important) and it is weighted more heavily when consumers make a choice than when they evaluate products, resulting in a choice-evaluation discrepancy. Consumers overweigh environmental friendliness in choice because it is emotion-laden and sacred, and therefore they avoid trading it off against other attributes [16]. Luce [16] demonstrated in her study, for example, that participants were more likely to choose an expensive but very safe car instead of a cheap but appropriately safe one because safety was emotion-laden. Extending this idea, sacred or protected values were developed to express the idea that certain values and moral principles are non-negotiable and thus are protected from trade-offs with other values. A sacred value has been defined as "any value that a moral community implicitly or explicitly treats as possessing infinite or transcendental significance that precludes comparisons, trade-offs, or indeed any other mingling with bounded or secular values" ([17] p. 853). Trading sacred values (e.g., human life, health, or human rights) off against secular values (e.g., money) is considered taboo. For instance, people struggle to protect sacred values from trade-offs against other values and respond with strong moral outrage when faced with violations of taboo trade-offs [18].

Our proposition is supported by several recent experimental findings. For example, in an experiment, participants were less inclined to purchase an illegally manufactured thumbnail-sized plastic storage device when a legally manufactured one was recommended through online recommendation systems [11]. This suggests that when consumers make a choice between two products, a CSR product penalizes a competing non-CSR product. Another experiment demonstrated that local, fresh produce receives the highest preference ranking, while organic products received the highest price premium [19]. These findings confirm that consumer preference for sustainable food products shows a classic phenomenon of preference reversal.

Imagine that you have two powder compact foundations. One product has a recycled package but cannot cover the face thoroughly and the other product does not have a recycled package but covers the face thoroughly. The former product is superior on an environmentally friendly attribute and inferior on a quality attribute compared to the latter product. When consumers are asked to choose between the two options, consumers will place greater weight on the environmentally friendly attribute because it is more prominent than the quality attribute. However, when consumers are asked to evaluate the two options, they will consider the two attributes equally important and then evaluate them in a graded pair comparison way. This suggests that the former option is more likely to be chosen even though it is not evaluated higher than the latter option.

Hypothesis 1. Choice is greater than evaluation of environmentally friendly products.

\subsection{Goals}

Goals shape consumers' choice and evaluation. Consumers consider goal-relevant attributes important when they develop knowledge [20] or when they make a purchase decision [21]. For example, Huffman and Houston [20] demonstrated that when participants learned how to carry a guitar comfortably, they recalled a goal-relevant attribute (e.g., body wood) better than a goal-irrelevant attribute (e.g., pickups). Similarly, people 
tend to pay attention to goal-relevant information. In one study, when participants were asked to gather information from a website, they concentrated on what will remain as the residue after reading. However, when they approached the same website to entertain, they enjoyed the rhythms and metaphors of the text [22].

We propose that when consumers pursue different goals, they will place weights on environmentally friendly attributes and quality attributes differently and thus make systematically different choices and evaluations. Imagine again that consumers consider buying one of two powder compact foundations. When they pursue environmentally friendly goals and consider the degree to which these options are environmentally friendly, environmentally friendly attributes are ranked highly regardless of whether options are chosen or evaluated, which removes the discrepancy between choice and evaluation. When consumers consider how strong two foundations work, they will place greater weight on quality attributes and thus a choice-evaluation discrepancy disappears again.

Hypothesis 2a. When consumers pursue quality goals, choice is the same as the evaluation of environmentally friendly products.

Hypothesis $\mathbf{2 b}$. When consumers pursue environmentally friendly goals, choice is the same as the evaluation of environmentally friendly products.

\section{Experiment}

\subsection{Method}

\subsubsection{Stimuli}

In this study, powder compact foundations, a type of cosmetics, were selected as stimuli. The reason is that the cosmetic market is one of the fastest growing industries in the world [23] and one of the industries receiving the most attention due to environmental problems caused by cosmetic packaging which contains a number of toxic materials [24-26]. We choose color cosmetic products rather than skin care products because, in the case of skin care products, the definition of environmentally friendly products may be ambiguous. In the case of skin care products, it is possible to interpret the quality aspect that is good for the skin because there are no chemical components rather than a product that is beneficial to the environment. Among color cosmetic products, we select the powder compact foundation that is relatively easy to evaluate and clear on quality.

According to past studies, consumers make decisions based on quality, package, price, brand, and price attributes when choosing cosmetics [27]. Research on environmentally friendly products has considered that environmentally friendly products may be more expensive than other products or may have lower quality. In this study, we aim to focus on the trade-off between environmentally friendly attributes and quality; therefore, brand and price information, which are the factors that can influence purchasing decisions, was not given to participants. In addition, information related to the amount of product (e.g., capacity), which is information that must be specified when selling cosmetics in Korea, where the experiment was conducted, is also presented. More specifically, the quality of cosmetics, one of most important determinants of cosmetic purchase, refers to how much it can contribute to making consumers appear more beautiful and attractive as an evaluation of what can best help to build and maintain the confidence of target customers [27,28]. Therefore, in this study, the quality attribute of powder compact foundation was specified as the coverage and the environmentally friendly attribute was expressed as an "environmental-friendliness evaluation" - the evaluation result based on the minimization of environmental pollution and the possibility of packaging recycling.

Participants were presented with a pair of powder compact foundations which present a trade-off relationship. We manipulated the superiority and inferiority of attributes by borrowing the method used by Chitturi et al. [29]. Each option consists of the two attributes which have a trade-off relationship: a quality attribute (coverage) and an environmentally friendly attribute (environmental friendliness evaluation). Information about 
quantity is identical (10 g). However, one option scores high on the quality attribute (coverage $=\star \star \star \star \star \star$ ) and low on the environmentally friendly attribute (environmental friendliness evaluation $=\star$ ). The other option scores low on the quality attribute and high on the environmentally friendly attribute (coverage $=\star \star \star$ and environmental friendliness evaluation $=\star \star \star \star \star \star)$. This attribute evaluation method is often used by SNS influencers (e.g., beauty bloggers) when reviewing cosmetics in Korea. The stimulus used in the experiment is shown in Table 1.

Table 1. Stimuli.

\begin{tabular}{ccc}
\hline & $\begin{array}{c}\text { Powder Compact } \\
\text { Foundation A }\end{array}$ & $\begin{array}{c}\text { Powder Compact } \\
\text { Foundation B }\end{array}$ \\
\hline Capacity & $10 \mathrm{~g}$ & $10 \mathrm{~g}$ \\
\hline $\begin{array}{c}\text { Environmental-friendliness } \\
\text { evaluation: the minimization } \\
\text { of environmental } \\
\text { pollution/the possibility of } \\
\text { packaging recycling }\end{array}$ & $\begin{array}{c}\star \star \star \star \star \star \\
\text { (Harmless to the } \\
\text { environment) }\end{array}$ & $\begin{array}{c}\star \\
\text { (Harmful to the environment) }\end{array}$ \\
\hline Coverage & $\begin{array}{c}\star \star \star \\
\text { (Moderate coverage) }\end{array}$ & $\begin{array}{c}\star \star \star \star \star \star \\
\text { (Excellent coverage) }\end{array}$ \\
\hline
\end{tabular}

\subsubsection{Design}

This study has a two (Mode: Choice vs. Evaluation) by three (Goal: Control vs. Quality vs. Environmentally friendly) between-subjects design. First, participants in the choice mode condition were asked to choose between two options. In the evaluation mode condition, participants were asked to evaluate two options on a seven-point Likertscale from 1 (definitely like option A) to 7 (definitely like option B). Second, goals were manipulated by instruction. Participants in the control goal condition read no instruction; participants in the quality goal condition read the sentence "You are now buying one of the two compact foundations in order to look young and beautiful"; and participants in the environmentally friendly goal condition read "You are now buying one of the two compact foundations in order to minimize the waste of buying new foundations."

\subsubsection{Procedure}

The experiment was conducted with a questionnaire, before the onset of COVID-19, and was conducted face-to-face with 165 college students attending three major universities in Seoul, Korea. According to recent studies, millennials, including college students, have a greater interest in the environment than other generations and have the most positive attitude toward environmentally-friendly consumption. In this study, the experiment was conducted preferentially on college students with relatively high environmental awareness. The subjects were students taking marketing-related lectures at three universities and participated in this study for an hour's course credit. The experiment took about 15 min, and all information except for participation was anonymous. Most of the participants were in their $20 \mathrm{~s}(89.5 \%)$ and $59.9 \%$ were male. In the past, the targets of cosmetic marketing were mainly limited to women, but the consumption of men's cosmetic is rapidly increasing, especially among millennials [30]. In facts, the men's cosmetics market shows the highest market growth rate in the cosmetics sector in Korea, and the increase in demand for color cosmetics accounts for a high proportion of this growth. Among color cosmetics, the consumption of concealers and foundations that hide skin imperfections make up the largest proportion [30]. In fact, in each experimental condition, gender did not have a significant effect on the dependent variable (choice condition: $\mathcal{X}^{2}(1)=0.672, p>0.1$; Evaluation condition: $\mathcal{X}^{2}(1)=0.212, p>0.1$ ). For this reason, in this study, gender effect was not taken into consideration. We briefly explained the function and role of the foundation in order to minimize the effect of personal differences in knowledge about cosmetics before the experiment. 


\subsubsection{Measurement}

First, we collected information about which option participants chose or evaluated highly. To make a consistent format between choice and evaluation, we converted scale data to binary data by adopting the method used in previous research on the topic of preference reversal $[15,29]$. For example, when the evaluation score fell between 1 and 3 , it was converted to 1 . When the evaluation score fell between 5 and 7 , it was converted to 2 . When the evaluation score was 4 , it was dropped. Note that we dropped only eight data points among 165 data points. Secondly, we measured the perceived importance of two attributes in each condition as well. Subjects were asked to evaluate how important each attribute (e.g., environmentally friendly attribute, quality attribute) would be in evaluating a powder compact foundation on a 7-point scale anchored by 1 (not at all important) and 7 (very important).

\subsection{Results}

\subsubsection{Choice-Evaluation Discrepancy}

We obtained evidence supporting Hypothesis 1 by comparing the percentage of the participants who chose and who evaluated highly the environmentally friendly option in the control goal condition. When asked to choose, $76 \%$ of the participants chose the environmentally friendly option. However, when asked to evaluate, only $49 \%$ indicated the environmentally friendly option as better. Two scores differed significantly $\left(\mathcal{X}^{2}(1)=5.043, p=0.022\right)$, suggesting that choice is greater than evaluation for the environmentally friendly option.

\subsubsection{Choice-evaluation Discrepancy and Goal}

We further obtained evidence partially supporting Hypothesis 2. In total, we obtained two sets of two-way interactions of mode and goal.

The first two-way interaction of mode and goal is between the control goal condition and the quality goal condition $\left(\mathcal{X}^{2}(1)=7.270, p=0.006\right)$. Unfortunately, asking participants to pursue the quality goal did not eliminate the discrepancy between choice and evaluation. In the quality goal condition, choice was significantly greater than evaluation for the environmentally friendly option ( $52 \%$ vs. $\left.23 \%, \mathcal{X}^{2}(1)=3.725, p=0.052\right)$. Note that although Hypothesis 2-1 was not statistically supported, pursuing the quality goal drops the gap between choice and evaluation of the environmentally friendly option, consistent with the direction of manipulation.

The second two-way interaction of mode and goal is between the control goal condition and the environmentally friendly goal condition $\left(\mathcal{X}^{2}(1)=4.484, p=0.027\right)$. Asking participants to pursue the environmentally friendly goal successfully eliminated the choiceevaluation discrepancy. In the environmentally friendly condition, choice did not differ from evaluation of the environmentally friendly option $\left(64 \%\right.$ vs. $55 \%, \mathcal{X}^{2}(1)=0.434$, $p=0.359$ ), supporting Hypothesis 2-2 (see Figure 1 and Table 2). 


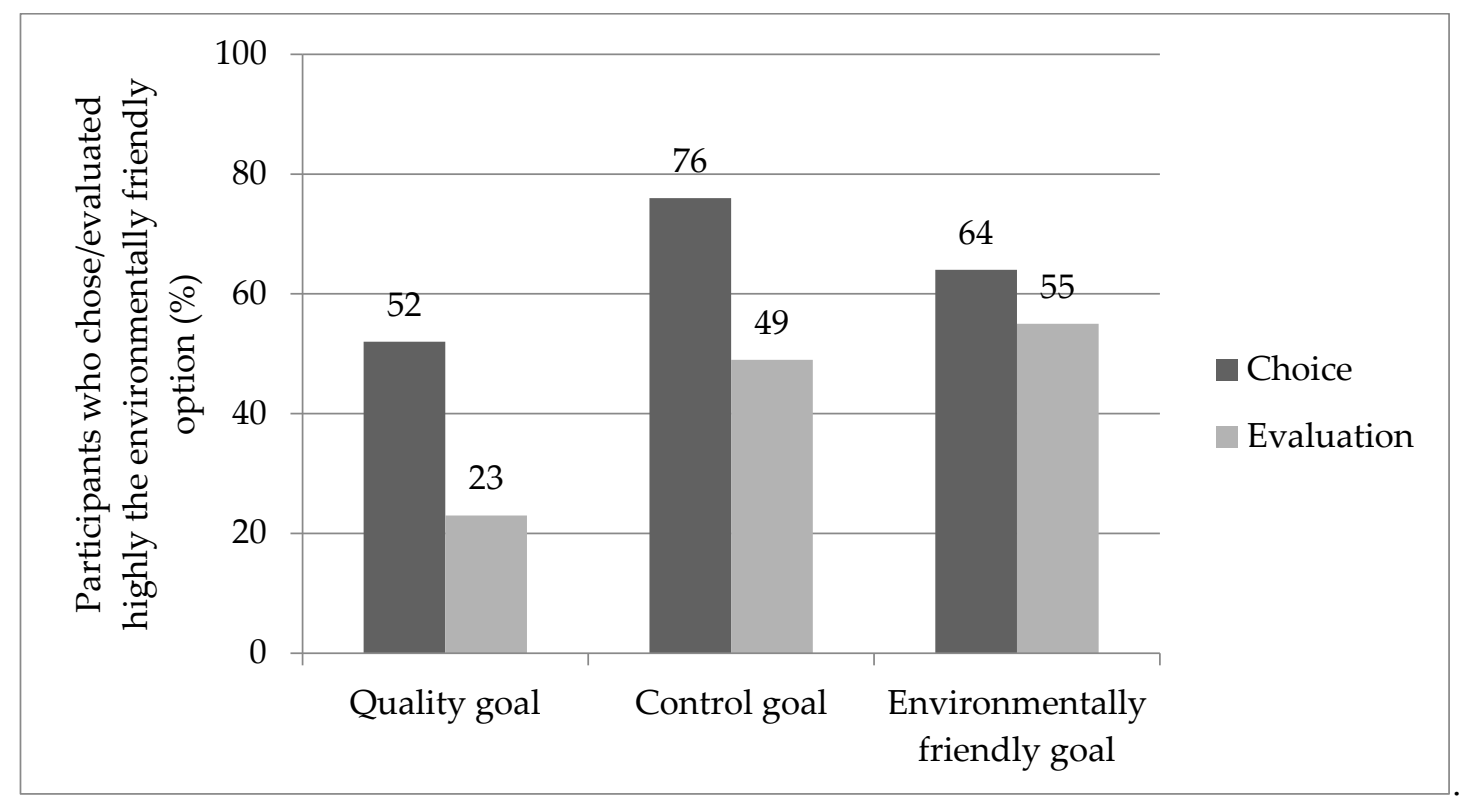

Figure 1. Percentage of the participants who chose/evaluated highly the environmentally friendly product as the function of goal.

Table 2. Percentage of the participants who chose or evaluated highly the environmentally friendly option.

\begin{tabular}{cccc}
\hline Mode $\backslash$ Goal & Quality Goal & Control Goal & $\begin{array}{c}\text { Environmentally } \\
\text { Friendly Goal }\end{array}$ \\
\hline Choice & 52 & 76 & 64 \\
Evaluation & 23 & 49 & 55 \\
\hline & $X^{2}(1)=3.725$ & $X^{2}(1)=5.043$ & $X^{2}(1)=0.434$ \\
& $p=0.052$ & $p=0.022$ & $p=0.359$ \\
\hline
\end{tabular}

\subsubsection{Choice-Evaluation Discrepancy and Relative Importance}

Finally, we analyzed the relative importance between the environmentally friendly attribute and the quality attribute. As expected, participants indicated that the environmentally friendly attribute was more important than the quality attribute in the choice mode $(-0.217)$ than in the evaluation mode $(-0.974, F(1,151)=3.769, p=0.054)$. Among the three goals, we found a significant difference in relative attribute importance in the control goal condition $(0.156)$ and in the quality goal condition $(-1.607, p=0.054)$. However, we did not find a statistical difference in relative attribute importance between the control goal condition and the environmentally friendly goal condition $(-0.335, p=0.287)$. Notice that attribute weight is inconsistent with our findings about choice and evaluation, suggesting that consumers do not necessarily follow their attribute weight to make a choice or evaluate options (see Figure 2). 


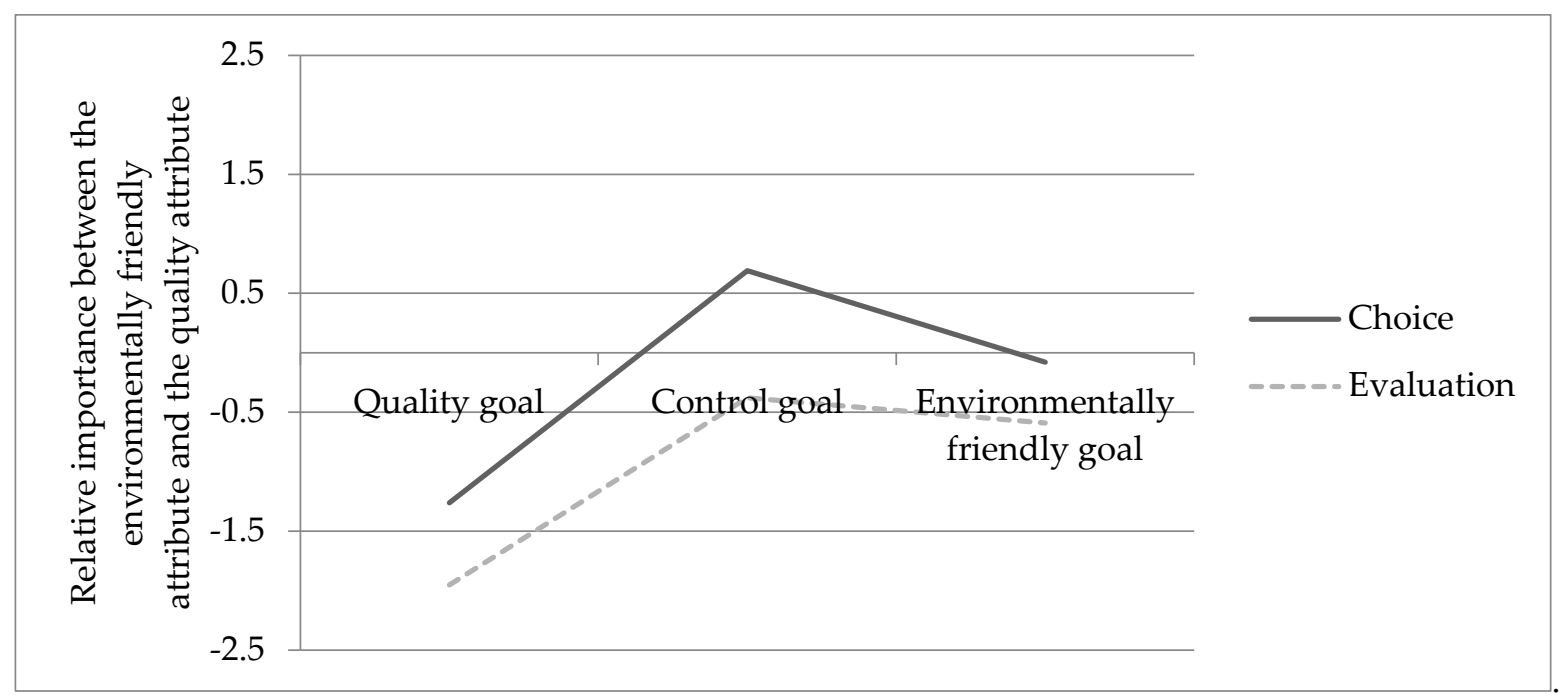

Figure 2. Relative importance between the environmentally friendly attribute and the quality attribute as the function of goal.

\section{General Discussion}

In the present work, we have two purposes. First, we aimed to demonstrate a rarely discussed intention-action gap in the context of environmentally friendly consumptionthat is, people act in spite of their intentions. Second, we did not merely demonstrate the gap but suggested a way to close it so that people can be seen to act according to their intentions. We borrowed the insights and findings from the psychological literature on choice-evaluation discrepancies and goals to develop two hypotheses and then conducted a carefully designed experiment. In the experiment, participants were asked to choose or evaluate two cosmetic products in three different conditions.

Our findings supported our hypotheses. First, most of the participants in the choice condition selected the environmentally friendly product even though only half of the participants in the evaluation condition ranked it higher, supporting H1. Second, when participants pursued a quality goal by reading the sentence "You are now buying one of the two compact foundations in order to look young and beautiful," the choice-evaluation discrepancy decreased, though not in a way that was statistically significant (H2-1). Third, when participants pursued an environmentally friendly goal by reading "You are now buying one of the two compact foundations in order to minimize the waste of buying new foundations," the choice-evaluation discrepancy disappeared, supporting H2-2. (See the summary of the hypotheses, findings, and test results in Table 3.)

Table 3. Hypotheses, findings, and test results.

\begin{tabular}{ccc}
\hline Hypothesis & Finding & Test Result \\
\hline $\begin{array}{c}\text { H1: Choice is greater than } \\
\text { evaluation of environmentally } \\
\text { friendly products. }\end{array}$ & $\begin{array}{c}\text { Choice }=76 \% \text { vs. evaluation }=49 \% \\
\left(\mathcal{X}^{2}(1)=5.043, p=0.022\right)\end{array}$ & Supported \\
\hline $\begin{array}{c}\text { H2a: When consumers pursue } \\
\text { quality goals, choice is the same as } \\
\text { evaluation of environmentally } \\
\text { friendly products. }\end{array}$ & $\begin{array}{c}\text { Choice }=52 \% \text { vs. evaluation }=23 \% \\
\left(\mathcal{X}^{2}(1)=3.725, p=0.052\right)\end{array}$ & Not supported \\
\hline $\begin{array}{c}\text { H2b: When consumers pursue } \\
\text { environmentally friendly goals, } \\
\text { choice is the same as evaluation of } \\
\text { environmentally friendly products. }\end{array}$ & $\begin{array}{c}\text { Choice }=64 \% \text { vs. evaluation }=55 \% \\
\left(\mathcal{X}^{2}(1)=0.434, p=0.359\right)\end{array}$ & Supported \\
\hline
\end{tabular}


Our findings primarily contribute to the research on environmentally friendly consumption by introducing a novel perspective and shedding light on a rarely discussed aspect of consumer behavior. Much prior research regarding the intention-action gap of environmentally friendly consumption focuses on strong intentions and weak action, explaining why people hesitate to buy a product with an environmentally friendly attribute and proposing ways of mitigating hesitancy. Some suggested making sustainable behavior the default, assisted by prompt and feedback [3], while others proposed the activation of status motives or encouraging consumers to make purchase decisions in a conspicuous context $[4,5]$. For example, a study showed that when the package color was environmentally friendly (e.g., blue), consumers' preferences for environmentally friendly products increased as the purchase context became more conspicuous [31]. Contrary to prior research, we focus on weak intentions and strong action. Our experimental findings reveal that consumers could purchase an environmentally friendly product even though their evaluation of it is not high. We believe our findings explain why some eco-friendly products are excessively popular (e.g., Starbucks' reusable cups) or can be sold at extremely high prices (e.g., Jil Sander's brown bag).

Our findings also contribute to the psychological literature on choice-evaluation discrepancies. In the past, when researchers conducted experiments to elaborate why people choose a product they do not evaluate highly, they used hypothetical stimuli such as bets, computers, and mobile phones [6,7]. One of the rarely observed practical applications of choice-evaluation discrepancy research could be found in conjoint analysis. According to the lessons from the 20 years of conjoint research, "choices reflect $20-30 \%$ greater emphasis on the most important attributes and put 30-40\% more weight on the least preferred levels of each attribute" [8], p. 1. As the psychological research was successfully applied to and then significantly improved conjoint analysis, our research may also be used to benefit environmentally friendly decision-making [8].

Our findings will also provide marketers with deep insights about consumers. As suggested by the literature on the topic of preference reversal and is supported by our experimental findings, consumers either increase or decrease their preference for an identical environmentally friendly product depending on how the item is presented. This suggests that marketers do not only pay attention to identify who will buy environmentally friendly products [5] but also how they should nudge people to buy them. Since our findings demonstrate that consumers tend to heighten their preferences for an environmentally friendly product when making a choice, marketers are suggested to ask consumers to make a choice rather than to reveal their evaluations. Note, however, that this strategy may not work when consumers pursue their own environmentally friendly goals, as suggested by our findings. Since consumers are frequently exposed to news articles about, e.g., extreme weather or climate change, their environmental goals are often activated and choice-evaluation discrepancies also disappear.

Note that the findings reported in this work have two critical limitations. First, we used a single product as a stimulus, employed hypothetical attributes, and employed starrating values. To extend our obtained findings, researchers might consider multiple stimuli with different product types, employ real attributes, and employ verbal values. Second, we claimed that a choice-evaluation discrepancy is observed because environmentally friendly attributes are prominent. However, the same discrepancy can be observed due to other characteristics of attributes. To deepen our obtained findings, researchers need to further test our hypothesis by seeing whether choice-evaluation discrepancies can be found with respect to other aspects of the variables, such as quantitative vs. qualitative [32], highly evaluable vs. less evaluable [33], or abstract vs. concrete [34]. Third, we conducted the experiment with a sample of college students-a relatively homogeneous group. Although there is a large amount of research showing that millennials have a high interest in and sensitivity to the environment, it is necessary to reconfirm the results of this study with other generations and socio-demographic groups. Finally, we used only a choice task and an evaluation task as response modes. In future research, it will be necessary to examine the 
differential effect of the WTP (Willingness To Pay), another response mode, on preferences for environmental friendly products.

Author Contributions: Conceptualization, B.J. and J.J.; experimentation, B.J.; data analysis and conclusion, B.J.; writing—original draft preparation, B.J. and J.J.; writing—review and editing, J.J.; supervision, B.J. and J.J.; project administration, B.J. and J.J.; first author, B.J.; corresponding author, J.J. All authors have read and agreed to the published version of the manuscript.

Funding: This research received no external funding.

Institutional Review Board Statement: Participants participated in our experiment voluntarily. They were fully informed about the ethical code of the study and agreed to attend the study. There was no risk involved with our experiment. Since our experiment asked participants to indicate their subjective opinions regarding a hypothetical product in a typical consumption situation anonymously in Korea, there was no need to obtain an ethics review report from any university. No personal data were collected and the questionnaire submitted to participants did not demand any legal measures required by the GDPR regulation of the EU or any regulations of Korea.

Informed Consent Statement: All participants submitted their informed consent statement before participating in the study.

Data Availability Statement: Not applicable.

Conflicts of Interest: The authors declare no conflict of interest.

\section{References}

1. Feber, D.; Granskog, A.; Lingqvist, O.; Nordigården, D. Sustainability in Packaging: Consumer Views in Emerging Asia; McKinsey \& Company, 2021; Available online: https://www.mckinsey.com/ \{\}/media/McKinsey/Industries/PaperandForestProducts / OurInsights/SustainabilityinpackagingConsumerviewsinemergingAsia/Sustainability-in-packaging-Consumer-views-inemerging-Asia.pdf?shouldIndex=false (accessed on 4 November 2021).

2. Tonby, O.; Razdan, R.; Woetzel, J.; Seong, J.; Cho, W.; Smit, S.; Yamakawa, N.; Devesa, T. Beyond Income: Redrawing Asia's Consumer Map; McKinsey \& Company, 2021; Available online: https://www.mckinsey.com/featured-insights/asia-pacific/ Beyond-income-Redrawing-Asias-consumer-map (accessed on 4 November 2021).

3. White, K.; Hardisty, D.J.; Habib, R. The Elusive green consumer. Harv. Bus. Rev. 2019, 125-133.

4. Griskevicius, V.; Tybur, J.; van den Bergh, B. Going Green to Be Seen: Status, Reputation, and Conspicuous Conservation. J. Personal. Soc. Psychol. 2010, 98, 392-404. [CrossRef]

5. Yoon, Y.; Chastagner, K.; Joo, J. Inner-self vs. outer-self and socially responsible product consumption. Sustainability 2020, $12,9362$. [CrossRef]

6. Lichtenstein, S.; Slovic, P. Reversals of preference between bids and choices in gambling decisions. J. Exp. Psychol. 1971, 89, 46-55. [CrossRef]

7. Bettman, J.R.; Luce, M.F.; Payne, J.W. Constructive Consumer Choice Processes. J. Consum. Res. 1998, 25, 187-217. [CrossRef]

8. Huber, J. What We Have Learned From 20 Years of Conjoint Research; Research Paper Series; Sawtooth: Washington, DC, USA, 1997.

9. Mostafa, M.M. Gender differences in Egyptian consumers' green purchase behaviour: The effects of environmental knowledge, concern and attitude. Int. J. Consum. Stud. 2007, 31, 220-229. [CrossRef]

10. Creyer, E.H.; Ross, W.T. The impact of corporate behavior on perceived product value. Mark. Lett. 1996, 7, 173-185. [CrossRef]

11. Yoon, Y.; Fu, Y.; Joo, J. Unintended CSR violation informed by online recommendation. Sustainability 2021, 13, 4053. [CrossRef]

12. Luchs, M.G.; Naylor, R.W.; Irwin, J.R.; Raghunathan, R. The sustainability liability: Potential negative effects of ethicality on product preference. J. Mark. 2010, 74, 18-31. [CrossRef]

13. Lin, Y.-C.; Chang, C.-C.A. Double standard: The role of environmental consciousness in green product usage. J. Mark. 2012, 76, 125-134. [CrossRef]

14. Tversky, A.; Sattath, S.; Slovic, P. Contingent Weighting in Judgment and Choice. Psychol. Rev. 1988, 95, 371-384. [CrossRef]

15. Fischer, G.W.; Scott, A. Hawkins. Strategy Compatibility, Scale Compatibility, and the Prominence Effect. J. Exp. Psychol. Hum. Percept. Perform. 1993, 19, 580-597. [CrossRef]

16. Luce, M.F. Choosing to avoid: Coping with negatively emotion-laden consumer decisions. J. Consum. Res. 1998, 24, 409-433. [CrossRef]

17. Tetlock, P.E.; Kristel, O.V.; Elson, S.B.; Green, M.C.; Lerner, J.S. The psychology of the unthinkable: Taboo trade-offs, forbidden base rates, and heretical counterfactuals. J. Personal. Soc. Psychol. 2000, 78, 853. [CrossRef]

18. Tetlock, P.E. Thinking the unthinkable: Sacred values and taboo cognitions. Trends Cogn. Sci. 2003, 7, 320-324. [CrossRef]

19. Chen, X.; Gao, Z.; McFadden, B.R. Reveal Preference Reversal in Consumer Preference for Sustainable Food Products. Food Qual. Prefer. 2020, 79, 1-13. [CrossRef] 
20. Huffman, C.; Houston, M.J. Goal-Oriented Experiences and the Development of Knowledge. J. Consum. Res. 1993, $20,190-207$. [CrossRef]

21. Ratneshwar, S.; Barsalou, L.W.; Pechmann, C.; Moore, M. Goal-derived categories: The role of personal and situational goals in category representations. J. Consum. Psychol. 2001, 10, 147-157. [CrossRef]

22. Schlosser, A.E. Experiencing products in the virtual world: The role of goal and imagery in influencing attitudes versus purchase intentions. J. Consum. Res. 2003, 30, 184-198. [CrossRef]

23. Kumar, S. Exploratory analysis of global cosmetic industry: Major players, technology and market trends. Technovation 2005, 25, 1263-1272. [CrossRef]

24. Statista. 2020. Available online: https://www.statista.com/statistics/243959/breakdown-of-the-cosmetic-market-worldwidebygeographic-zone/ (accessed on 25 March 2021).

25. Chhetri, S.; Fernandes, S.; Baby, S. Validating purchase intentions for green cosmetic products: Appling and extendintheory of planned behavior. Inf. Technol. Ind. 2021, 9, 773-789.

26. Cinelli, P.; Coltelli, M.B.; Signori, F.; Morganti, P.; Lazzeri, A. Cosmetic packaging to save the environment: Future perspectives. Cosmetics 2019, 6, 26. [CrossRef]

27. Anjana, S.S. A study on factors influencing cosmetic buying behavior of consumers. Int. J. Pure Appl. Math. 2018, 118, 453-459.

28. Priyanga, P.; Krishnaveni, R. Perception of women consumer towards branded cosmetics in Nagapattinam District. Int. J. Sci. Res. 2016, 5, 652-654.

29. Chitturi, R.; Raghunathan, R.; Mahajan, V. Form versus function: How the intensities of specific emotions evoked in functional versus hedonic trade-offs mediate product preferences. J. Mark. Res. 2007, 44, 702-714. [CrossRef]

30. Jeong, G.Y.; Chae, M.S. A Study on Actual Status of Using Color Cosmetics of Male Singles: On the Male Single between 20 to 39 years. J. Glob. Bus. Res. 2015, 17, 55-67.

31. Doo, M.; Joo, J. The Impact of Purchase Context on the Preferences for Environmentally Friendly Products: Moderated by Package Color. Arch. Des. Res. 2016, 29, 157-167. [CrossRef]

32. Nowlis, S.M.; Simonson, I. Attribute-Task Compatibility as a Determinant of Consumer Preference Reversals. J. Mark. Res. 1997, 34, 205-218.

33. Chen, X.; Kim, S.; Joo, J. How do we nudge people to choose aesthetically pleasing products? Arch. Des. Res. 2019, 32, 61-73. [CrossRef]

34. Nguyen, T.T.; Joo, J. Digital strikes back: Reading digital clocks decreases new product adoption. Arch. Des. Res. 2019, 32, 103-115. 